\title{
Helicobacter pylori and gastric histamine concentrations
}

\author{
D M M Queiroz, E N Mendes, G A Rocha, J R Cunha-Melo, A J A Barbosa, \\ G F Lima Jr, C A Oliveira
}

\begin{abstract}
An enzyme isotopic assay was used to determine the histamine concentration in the gastric mucosa of patients positive for Helicobacter pylori with $(n=11)$ and without duodenal ulceration $(n=9)$ and in negative controls $(n=7)$. A significant difference was observed when the histamine content of $H$ pylori negative subjects was compared with that of positive patients. On the other hand, there was no significant difference in histamine concentration between $H$ pylori positive patients with duodenal ulceration and those without duodenal ulceration. $H$ pylori positive patients with and without duodenal ulceration had significantly lower gastric histamine concentrations than $H$ pylori negative subjects. The lower gastric histamine concentration observed in $H$ pylori positive patients might be due to increased histamine release which could in turn induce increased gastric acid secretion.
\end{abstract}

The pathogenesis of duodenal ulceration is not yet fully understood, but it is thought that duodenal ulceration arises from a disturbance in the balance of acid production and mucosal resistance. Helicobacter pylori has been observed in up to $100 \%$ of subjects with duodenal ulceration and its elimination by antibiotics leads to healing of the ulcer. ${ }^{1-2}$ Although the link between $H$ pylori and duodenal ulceration is complex, it has been suggested that the micro-organism could cause ulceration by damaging the duodenal mucosa ${ }^{3}$ as well as by increasing acid secretion. ${ }^{4}$ According to Levi et al the urease produced by $H$ pylori transforms urea into ammonia, raising the antral surface $\mathrm{pH}$, which increases serum gastrin and thus acid secretion. ${ }^{4}$ Their hypothesis was contested by Treiber, ${ }^{5}$ who affirmed that $H$ pylori does not influence acid secretion.

As histamine has been proposed as the common mediator for all gastric secretions, including gastrin, this study was carried out to determine the histamine concentration in the gastric mucosa of $H$ pylori positive and negative patients with and without duodenal ulceration.

\section{Methods}

Twenty seven patients presenting for endo- scopy due to upper gastrointestinal complaints were studied. None of them had received antibiotics, histamine- 2 receptor antagonists, or any medication for at least one month before the study. Eleven were $H$ pylori positive with endoscopically confirmed duodenal ulceration (eight men mean age $40 \cdot 8$ years); nine were $H$ pylori positive with histologically confirmed gastritis but no duodenal ulceration (six men mean age 41.9 years); and seven were $H$ pylori negative without duodenal ulceration (six men mean age $42 \cdot 2$ years).

This project was approved by the ethics committee of Hospital das Clinicas, Universidade Federal de Minas Gerais, Brazil, and informed consent was obtained from all patients.

Biopsy specimens were taken from the antral and body mucosa for histological examination: preformed urease test, a smear stained by carbol fuchsin, and culture were used to identify $H$ pylori.

Three fragments taken from the gastric body mucosa of each patient were immediately frozen and stored in liquid nitrogen until processing.

Histamine was extracted according to the method of Synder et $a l,{ }^{6}$ but slightly modified. The tissues were weighed while thawing, immediately immersed in $0 \cdot 1 \mathrm{M}$ phosphate buffer saline (PBS), pH $7.9(1 \mathrm{~g} / 20 \mathrm{ml})$ in a plastic tube, heated for 10 minutes in boiling water, and homogenised with a Teflon pestle tissue homogeniser (size 0, Thomas Scientific, Swedesboro, New Jersey, USA). The tubes were then centrifuged at $5000 \mathrm{rpm}$ at $4^{\circ} \mathrm{C}$ for 10 minutes and the supernatant was lyophilised.

The fluid was suspended in $100 \mu \mathrm{l}$ of $0.1 \mathrm{M}$ PBS, $\mathrm{pH} 7 \cdot 9$, for histamine assay. Aliquots of $10 \mu \mathrm{l}$ were mixed with $35 \mu \mathrm{l}$ of a reagent, which contained $0.05 \mathrm{M}$ PBS, $12 \mu \mathrm{l}$ of rat kidney histamine methyltransferase enzyme preparation, ${ }^{7}$ and $10 \mu \mathrm{l}$ of $20 \mu \mathrm{Ci} / \mathrm{ml}$ solution of $S$-[methyl-14C] adenosyl-L-methionine (specific activity $5 \mathrm{mCi} / \mathrm{mmol}$ ), and incubated at $37^{\circ} \mathrm{C}$ for 90 minutes. Twenty microlitres of $2 \% \mathrm{~N}$-methylhistamine dihydrochloride ( 1 in 4 methylhistamine dihydrochloride) (Sigma Chemical Co., St. Louis, Missouri, USA) in $1.5 \mathrm{M}$ perchloric acid was used to stop the reaction. A solution containing $20 \mu \mathrm{l}$ of $10 \mathrm{NaOH}$ and $500 \mu \mathrm{l}$ of a mixture of isoamylalcohol and toluene (20:80) was added to each tube. The tubes were capped, shaken for 10 minutes, and centrifuged for 60 seconds on a Beckman Microfuge (Beckman Instru- 
Histological findings in gastric mucosa of $H$ pylori positive and negative patients

\begin{tabular}{llll}
\hline & Positive & Negative \\
\cline { 2 - 4 } Mucosal histology & With duodenal ulceration $(n=11)$ & Without duodenal ulceration $(\boldsymbol{n}=9)$ & $(\boldsymbol{n}=7)$ \\
\hline Antrum & & 4 & 0 \\
ASCG & 8 & 2 & 1 \\
SCG & 3 & 3 & 0 \\
ACG & 0 & 0 & 6 \\
Normal & 0 & 2 & 0 \\
Body & 0 & 3 & 0 \\
ASCG & 2 & 1 & 0 \\
SCG & 0 & 3 & 7 \\
ACG & 9 & & \\
Normal & & &
\end{tabular}

ASCG: active superficial chronic gastritis; SCG: superficial chronic gastritis; ACG: atrophic chronic gastritis.

${ }^{\star}$ None of them had duodenal ulceration.

ments). Three hundred microlitres of the upper layer was transferred to $5 \mathrm{ml}$ of scintillation fluid for radioactive assay. The results were expressed as counts per minute and the calculation of histamine concentration/sample was based on a standard curve derived from known amounts of histamine.

Statistical analyses were carried out using the two tailed $t$ test. Differences of $\mathrm{p}<0.05$ were regarded as significant.

\section{Results}

A significant difference was observed when the histamine content (mean, (SD)) of $\mathrm{H}$ pylori negative subjects $(50.29(14.06) \mu \mathrm{g} / \mathrm{g}$ fresh weight) was compared with that of $H$ pylori positive patients with duodenal ulceration $(27.76(9.17) \mu \mathrm{g} / \mathrm{g})(\mathrm{p}=0.0008)$ and with gastritis but no duodenal ulceration (29.60 (11.64) $\mu \mathrm{g} / \mathrm{g})(\mathrm{p}=0.006)$. On the other hand, there was no significant difference in histamine concentration between $H$ pylori positive patients with duodenal ulceration and those with gastritis but without duodenal ulceration $(\mathrm{p}=0 \cdot 69)$. H pylori positive patients with and without duodenal ulceration showed significantly lower gastric histamine concentration $(28.58(10.11) \mu \mathrm{g} / \mathrm{g})$ than negative subjects $(\mathrm{p}=0.0002)$.

The histological findings are shown in the table.

\section{Discussion}

The use of a highly sensitive and specific method for determining the histamine concentration of body-type mucosa showed that $H$ pylori positive patients with duodenal ulceration as well as those with gastritis and without duodenal ulceration had a significantly lower gastric histamine concentrations than $H$ pylori negative subjects. We recently observed this in $H$ pylori positive children. ${ }^{8}$ Children with duodenal ulceration, however, presented with histamine concentrations lower than those without duodenal ulceration. We were unable to explain the observed differences between adults and children.

Several hypotheses could be advanced to explain the reduction in gastric histamine concentration that we observed in $H$ pylori positive patients. The most likely is that more histamine might be released with a subsequent depletion of stores. This might be induced by an increased release of gastrin following $H$ pylori infection, as shown by Levi et al. ${ }^{4}$ Moreover, as mast cells, which store histamine in human gastric mucosa, are also involved in the immunological process, the existence of gastritis might itself be sufficient to disturb histamine metabolism. Oxyntic gastritis was a feature of most of our $H$ pylori positive patients without duodenal ulceration, but most of them with duodenal ulceration had normal body mucosa. Nevertheless, all $H$ pylori positive patients had antral gastritis, and we do not know how this could disrupt histamine metabolism.

A second hypothesis to explain the lower histamine concentration observed in $H$ pylori positive patients is that it could be associated with a decrease in histamine production. On the other hand we found that patients with duodenal ulceration had increased gastric histamine concentrations after treatment with a histamine-2 receptor antagonist (data not shown), although they still had antral gastritis. This seems to indicate that gastritis does not decrease histamine production.

Another possibility is that histamine might have been inactivated. A previous study has shown, however, that histamine methyltransferase activity, the only enzyme able to inactivate histamine, is decreased in patients with duodenal ulceration. ${ }^{9}$

Therefore, our results seem to indicate that lower gastric histamine concentrations in $H$ pylori positive patients might be due to the high mobilisation of endogenous mucosal histamine with increased depletion of its stores which could, indirectly, induce an increased gastric acid secretion in these patients.

1 Graham DY. Campylobacter pylori and peptic ulcer disease. Gastroenterol 1989;96:615-25.

Marshall BJ, Goodwin CS, Warren JR, et al. Prospective double-blind trial of duodenal ulcer relapse after eradication of Campylobacter pylori. Lancet 1989;ii:1437-41.

3 Goodwin CS. Duodenal ulcer, Campylobacter pylori, and the leaking roof concept. Lancet 1988;ii:1467-9.

4 Levi S, Beardshall K, Haddad G, Playford R, Ghosh P, Calam J. Campylobacter pylori and duodenal ulcers: the gastric link. Lancet 1989;i:1167-8.

5 Treiber G. Campylobacter pylori and acid secretion. Lancet 1989;ii:212.

6 Snyder SH, Baldessarini RJ, Axelrod J. A sensitive and specific enzymatic isotopic assay for tissue histamine. $J$ Pharmacol Exp Ther 1966;153:544-9.

7 Shaff RE, Beaven MA. Increased sensitivity of the enzymatic isotopic assay of histamine measurement of histamine in plasma and serum. Anal Biochem 1979;94: plasma

8 Queiroz DMM, Mendes EN, Rocha GA, Barbosa AJA, Carvalho AST, Cunha-Melo JR. Gut 1991;32:464.

9 Pedem NR, Calachan H, Shepherd DM, Wormsley KG Gastric mucosal histamine and histamine methyltransferase in patients with duodenal ulcer. Gut 1982;23:58-62. 